\title{
Prevalência e classificação das recessões gengivais: estudo clínico observacional
}

\begin{abstract}
RESUMO
O propósito desse estudo foi avaliar a prevalência e características das recessões gengivais de acordo com os critérios estabelecidos na nova classificação das doenças e condições periodontais e peri-implantares, bem como seu impacto na qualidade de vida. Foram incluídos 50 indivíduos de ambos os sexos, $\geq 18$ anos, apresentando recessões gengivais vestibulares isoladas ou múltiplas. Os participantes foram examinados quanto às medidas de profundidade de sondagem (PS); perda de inserção clínica (PIC); sangramento à sondagem (SS) e índice de placa (IPl). Profundidade da recessão (ProfREC), altura de gengiva ceratinizada (AGC), espessura da gengiva (EG), presença de junção cemento-esmalte (JCE) detectável ou não (classes A e B, respectivamente) e presença (+) ou ausência (-) de degrau cervical também foram investigados. As recessões foram classificadas em 3 tipos: Recessão Tipo 1 (RT1), Recessão Tipo 2 (RT2) e Recessão Tipo 3 (RT3). O impacto das recessões na qualidade de vida foi determinado pelo questionário Oral Health Impact Profile (OHIP-14). Foram observadas 223 recessões em 1343 dentes analisados (16,60\%). O número médio de recessões/paciente foi de 4,40 $\pm 2,74$. Houve maior prevalência de recessões RT1 $(72,20 \%)$, localizadas na região de pré-molares superiores $(28,70 \%)$, apresentando em média $2,11 \pm 1,22 \mathrm{~mm}$ de profundidade. A EG média foi $1,11 \pm 0,38$, enquanto que AGC média foi de 2,56 $\pm 1,65 \mathrm{~mm}$, com predomínio de fenótipo gengival fino (51,12\%). EG $\leq 0,8 \mathrm{~mm}$ estava significativamente associada com recessão ( $p<0,0001$; teste exato de Fischer). Não houve diferenças significantes entre os grupos com e sem recessão relativamente aos parâmetros clínicos investigados, com exceção de PIC, que foi maior em dentes com recessão ( $p<0,0001$; Mann Whitney). Dentes com RT1 apresentaram menor média de ProfREC, EG, P.S., PIC e IP1 do que recessões RT2 e RT3 (p< 0,05; Kruskal Wallis pós-teste Dunn), com fraco impacto na qualidade de vida. Os resultados obtidos sugeriram que as recessões gengivais estão associadas com menor EG e AGC e maior PS, IP1 e PIC.
\end{abstract}

Palavras-chave: Recessão gengival. Gengiva. Prevalência. Classificação. Qualidade de vida. 